\title{
Time Management and Self-Motivation Skills Exhibited by Small Scale Business Operators for Successful Venture in Delta State of Nigeria
}

\author{
G. O. Onajite \\ Business Education Unit, Department of Vocational and Technical Education, Ekiti State University, Ado-Ekiti, Nigeria
}

Email address:

onajitego@gmail.com

To cite this article:

G. O. Onajite. Time Management and Self-Motivation Skills Exhibited by Small Scale Business Operators for Successful Venture in Delta State of Nigeria. International Journal of Business and Economics Research. Vol. 6, No. 2, 2017, pp. 25-31.

doi: $10.11648 /$ j.ijber.20170602.12

Received: October 30, 2016; Accepted: November 26, 2016; Published: April 28, 2017

\begin{abstract}
This study was conducted to determine the extent to which small scale business operators in Delta State of Nigeria exhibit time management and self motivation skills for successful venture in Delta State of Nigeria. Survey design was adopted for the study and it was guided by two research questions. Two null hypotheses were formulated for the study and they were tested at 0.05 level of significance. Twenty-five (25) small scale business operators were selected from each of the 25 local government areas of the state totaling 625 sample using stratified random sampling technique. The instrument for data collection was a structured questionnaire which was validated by experts in Business Education. The questionnaire before administration was subjected to a reliability test and the data generated therein were analyzed using Cronbach Alpha which yielded a coefficient index of 0.94. Data collected for the study were analyzed using Mean and Standard Deviation to answer the research questions while Analysis of Variance (ANOVA) and z-test were used to test the null hypotheses. The study found that operators of small scale businesses in Delta State of Nigeria exhibited time management and self-motivation skills to a high extent. Also, the test of the two null hypotheses revealed that urban and rural small scale business operators in Delta State did not differ significantly on their mean rating of the extent they possess self motivation skills and time management skills as a result of the academic qualifications. It was concluded that time management and self-motivation skills are paramount for successful operation of small scale businesses. It is hereby recommended among others that workshops and seminars should be organized for operators of small scale business and owners by the agencies responsible for the development of small businesses at all levels of government to create in-depth knowledge and technical know-how on time management and self motivation skills.
\end{abstract}

Keywords: Time Management, Self Motivation, Skills, Small Scale Business, Delta State

\section{Introduction}

In both developed and developing countries, the governments and the people are turning to small scale industries as a means of economic development and a veritable tool for solving their economic problems. Countries such as U. S. A., Japan, South Korea, Malaysia, India and Jamaica accord prominence to small business sector because of its contributions to the economic growth and stability of their nations [1]. Small scale businesses assist in promoting the growth of a country's economy. Agbonifoh [2] stated that small scale businesses have served as a vehicle for rapid industrialization, sustainable development, poverty alleviation and employment generation in many countries. Small scale businesses account for a large segment of productive population, and Nigeria falls within this segment of the economy, as small scale businesses account for over 95 percent of non-oil productive activities outside agriculture.

Globally, the definition of small scale businesses varies from country to country, depending on criteria considered most suitable to promote the sub-sector in each country. In Nigeria, the mostly used criteria for the definition of small scale businesses include, ownership structure, number of employees, capital outlay, annual turnover, nature of business and technology employed. The above criteria share common idea that small scale businesses are generally low in terms of 
the number of persons employed and in the amount of investment and annual business turnover. However, some of the major characteristics of small scale enterprises that are universally recognizable are that, they are typically small, because of limited access to financial resources, have simple management structure - which generally combines ownership and management in one person. The small scale enterprises use a lot of local inputs (raw materials), they are also widely dispersed in any economy. Many factors can make an individual decide to establish his/her own enterprise which can either be negative or positive. The negative factors include job dissatisfaction, lack of job challenges, pay dissatisfaction, unemployment, dependency, and job insecurity while the positive factors are encouragement by friends and government policies.

There are business skills which an individual needs to acquire to enable him or her function effectively in the competitive business environment as an entrepreneur or a self employed person. Ademola [3] identified some skills needed by entrepreneurs for successful management of small scale businesses as technical skills, human skills, conceptual skills, problem solving skills, high productivity skills, leadership skills, creativity skills, marketing and selling skills, negotiating skills, time management skills, self motivation skills, accounting and a range of interpersonal skills. The rationale for skill acquisition is likened to acquisition of competences necessary for self- reliance which can lead to one being gainfully or self employed. Time management and self motivation skills were assessed in this study because from the literature available to the researcher at the time of this study there were no empirical evidences showing that the two skills have been empirically assessed in Delta State of Nigeria. Also, the two skills are very critical in the present competitive business environment.

It is important to note that in the current complex and competitive business environment in Nigeria, a small business operator needs to have particularly skills for time management and self-motivation. Time management is about achieving meaning and purpose in life. The life of the small business owner is not the business, it is what the business enables the owner to achieve in life. Put properly, to manage over time is to manage for lives.

Similarly, Tijani-Alawe [4] opined that the absence of strategic management skills and attitude are responsible for business failure. This author was of the opinion that the inability to respond to threatening environmental conditions, lack of clearly defined objectives, lack of delegation, inability to select appropriate equipment, resources and the faulty design, implementation and evaluation by small scale businesses hampers growth of such businesses. The author also indicated that some of the problems faced by small scale entrepreneurs include lack of appropriate skills required to manage their businesses. Thus, it is pertinent to assess the skills (especially time management and self-motivation skills) possessed by small scale business operators in Delta State of Nigeria in order to reposition them.

\section{Literature Review}

\subsection{Time Management Skills}

Agbonifoh [2] submitted that the ability to plan your day and manage your time is particularly important for a home business. When you wake up in the morning, you must have a clear idea of the things you must do for the day, especially if you are running a one-person operation, you must have the ability to multi-task, e.g become the secretary at the start of the day typing all correspondences and emails, become the marketing man, writing press releases before noon, make sales call in the afternoon, and become a bookkeeper before your closing hours. Imagine if you are selling products and you still have to create the products, deliver and fulfill the orders, rush to the bank to cash the cheques. You simply have to know how to manage time and prioritize your tasks.

One difficulty of working from home is that you can never seem to stop. There are simply too many things to do, as if work never stops (and it doesn't). Part of having good time management skills is knowing when to stop and when to leave work and begin doing your other roles in your family as the husband, wife, mother or father. You must be able to know how to keep your home life separate from your work life and ensure that there exists a balance between the two.

On his part, Uloko [5] stated that the concept of time management cannot be effectively dealt with unless strategies for setting goals are included in its framework. The following time management program thus consists of goal setting; taking actions everyday to reach those goals; making sure each action is focused, relevant and results orientated; prioritizing which actions need to be done first or are the most important; and rethinking your goals when productivity suffers. There are some basic principles for time management which can be arranged into these five steps [5]:

STEP 1: Write down your seven most important goals. The first action here is to start by listing as many goals, values, dreams, focuses, needs, wants and strategies for accomplishment as you can.

Second, select your ten most important goals and arrange them from most important to least important. Once you have your top ten, cut out the last three because you probably won't remember them anyway. Now change each goal into a specific result. Don't write, "I want to be rich." Say, "I want one million dollars in mutual funds by the time I am 42." Don't say, "I want to be a musician," say, "I want to compose 20 songs and play them on my guitar from memory in one year."

Thirdly, now that you have a list of seven action orientated goals or rather focuses, write down as number eight your ultimate dream. Number eight may be the same as anyone of your top seven but most likely it will be a summary statement of ALL your goals. Number eight is your meaning in life and is your ultimate strategy for happiness and success.

1st NOTE - To help brainstorm about your most important goals, begin by fantasizing about what type of environment would allow your best self to emerge. Imagine what your ideal day would be like if you had no financial or time 
restraints. Also, imagine if you had seven lives to live what would they be? Pull from each life the one thing you value the most and blend those vital parts into the design.

2nd NOTE - Each major focus should be broken down into seven additional mini-strategies or goals giving you 49 ministrategies to your 7 major goals. For example, if living your life in good health is one of your seven most important goals, list seven actions you can do to reach that goal such as: cut down on refined sugar, eat more fiber, do 20 push-ups before you go to bed, jog two miles three times a week, reduce fat intake to $20 \%$ of calories, play with the kids more often, drink 6 glasses of water a day.

3rd NOTE - Big lists aren't better than small lists. Big lists are only unfocussed lists. If three of your top seven goals are significantly more important than your last four then maybe you don't need your last four.

STEP 2: Every day write down six or seven actions to be completed. It has been documented that people who sit down and plan their day in writing have a far greater chance of succeeding than those who do not make any plans. Writing reflects commitment. Therefore, start each day by writing down what you want to accomplish on any scrap of paper. If you find it useful to be more systematic, use a day planner. Keep in mind that if you mentally program yourself early in the day, you tend to organize, focus and pace yourself better. Right away your brain starts looking for solutions and shortcuts before you actually do anything.

1st NOTE - Six and seven are not magic numbers. In fact, concentrating on four, five or even eight actions a day will work nicely too. Six and seven are chosen because that's generally the most thoughts you can keep in your conscious mind at any time. If you limit yourself to one or two, you are not taking advantage of your brains processing power. If you write more than seven, like ten or twelve, you will likely be unable to maintain this level of production for very long and will eventually burn out.

2nd NOTE - Some people find it more effective to write down their six or seven actions each morning and others at the end of the previous day. Writing them down in the morning is practical and immediate. Writing them down at the end of your day for the following day, gives your subconscious the whole evening and while you're sleeping to work out solutions and strategies. This method also gives you a chance to review your daily accomplishments, giving you a greater sense of completion.

STEP 3: Make sure each daily action is focused, relevant and results orientated. When writing down your daily acprogress of your real priorities, consider menial unessential tasks as "breathers" or breaks from the real important ones. Use them to relax and regroup, not focus and fool yourself into thinking you are doing something remarkable.

Your daily actions should be results orientated. Whenever you have a choice between an action that shows results at the end of the day and one that does not, always pick the one that shows results. At the end of the day, like a carpenter when finished a cabinet, you must be able to look at what you've done and say; "hey that looks great!"
In other words, each of your completed actions should leave you with a sense of accomplishment. This is the key to maintaining motivation. A meeting where everyone brainstorms on new products than chooses a product to be marketed is results oriented, keeps people pumped and allow colleagues to give themselves and others a nice pat on the back. A meeting where everyone speaks his or her mind doesn't choose anything but gets it all out in the open, is really just group therapy. Remember that results don't have to be big but they do have to be tangible.

STEP 4: Prioritize, which actions need to be done first or which actions are the most important. One way to prioritize your six or seven most important daily actions is to simply number them from one to seven, one being the action that needs to be done first at the beginning of the day, two being the next action, and so on. As you complete each action simply cross it out, these methods is simple and above all else full proved. Whichever method you use, remember that prioritizing your daily action is only a tool not a way of life.

STEP5: Rethink your goals if productivity begins to suffer. If you end up doing the same thing day after day eventually you will get bored, your actions will become meaningless and your performance will suffer. At this point it's time to rethink your top seven goals and your summarizing mission statement.

If there's no way you can change your goals, then change the way you look at. Human beings are vibrant creatures and don't function well in ruts. Being able to adapt and reframe, is essential to progress.

As in [6], a successful entrepreneur has a good sense of timing. They believe "that time is money" and not easy to recover if wasted. The entrepreneur is over conscious about timely arrangement with all stake holders. They state further that time binding arrangement constitutes important aspects of entrepreneurial function in the Nigerian competitive business practices.

\subsection{Self Motivation Skills}

Onwuchekwa [7] sated that historically, the concept of motivation can be traced to two schools of psychological thought. One of these, the behavioural school, asserts that all behaviour is caused and the other, the cognitive school, claim that behaviour is goal-directed, that is every behaviour has a purpose. To say that behaviour is caused (stimulated) implies that all behaviour is determined or is predictable. On the other hand, the claim that all behaviour is motivated by a desire or need to attain goals, is not clear-cut because the specific goals are not always consciously known by the individual. Since people are not always aware of everything they want, much of their behaviour was bound to be affected by subconscious motives or needs. He states further that many studies have been carried out to determine the correlates of motivation [8]. The middle part of 20th century witnessed an upsurge of interest in theoretical formulations and empirical work on the issues surrounding the concept of motivation. Three notable authorities whose works have remained reference points include Maslow (needs theory), 
McGregor (Theory X and Theory V), and Herzberg (motivation - Hygiene or Two factor Theory).

Agbonifoh [2] commenting on self motivation, says as an entrepreneur, you do not have the luxury of bosses and bureaucracy to tell you what needs to be done. Everything rests on your shoulder from thinking where to get the money to fund the business, to developing the product, to determining how to reach the customer and so on. Only you will create the plans and change them should the situation shifts, and also be smart enough to know when you need to go ahead and when to stop.

To succeed in business, you must be a self-starter with a clear desired goal in mind. You must have the confidence in yourself, and in your ideas (how can you sell your ideas to others if you yourself do not believe in them?). More importantly, you must be willing to focus your energy and work hard towards each and every step that will make your enterprise a success. Especially if you work at home, it is doubly hard to get into the work mindset, sometimes the television is just too tempting that it is hard to get out of your pajamas and begin typing in your computer. You therefore must have that extra drive and commitment to make sure that you are taking the necessary steps to make your dream of a successful business a reality.

\section{Objectives and Hypotheses}

\subsection{Purpose of the Study}

The purpose of this study specifically was to assess the extent small scale business operators in Delta State exhibit time management and self motivation skills.

\subsection{Research Questions}

1 To what extent do small scale business operators in Delta State exhibit time management skills for successful venture?

2 To what extent do small scale business operators in Delta State exhibit self motivation skills for successful venture?

\subsection{Null Hypotheses}

The following null hypotheses were formulated.

1 Small scale business operators in Delta State do not differ significantly in their mean ratings of the extent they possess time management skills as a result of their academic qualifications.

2 Urban and rural small scale business operators in Delta State do not differ significantly in their mean ratings of the extent they possess self motivation skills.

\section{Method}

The research design adopted for this study was survey. As in [9], through survey researchers identify present conditions, prevailing needs as well as provide information on which to base sound decisions. Consequently, since this study involved assessing the opinions of small scale business operators on the time management and self-motivation skills they possess in Delta State, the survey design was considered appropriate.

The research was carried out in Delta State of Nigeria. The State presently has 25 local government areas with 14 towns designated as urban. The people of Delta State are predominantly farmers and small scale business operators because of the vegetation and the presence of large resources of petroleum and gas. The decision to use Delta State for the study was informed by the fact that the state has many small scale businesses which have failed or not doing well.

The population of the study consisted of all the 984 registered small scale business operators in Delta State of Nigeria. The data were made available by the Delta State Ministry of Commerce and Industries. Small scale businesses are spread over the 25 local government areas of the state. The sample was 625 registered small scale business operators drawn from the 25 local government areas of the state using stratified random sampling technique. Twenty-five (25) registered small scale business operators were selected from each of the 25 local government areas of the state to make up the sample of 625 for the study.

The instrument for data collection was a structured questionnaire. The questionnaire was developed by the researcher after careful study of related literature guided by the research questions. The questionnaire has three sections; Section A contains four items on respondents' personal data while the other two sections were organized in such a way that respondents expressed their opinions on a five-point scale as follows: Very High Extent (VHE), High Extent (HE), Moderate Extent (ME), Low Extent (LE), No Extent (NE) based on the research questions.

The face and content validity of the instrument were established by two experts of Business Education from the University of Benin, Nigeria. Their inputs were incorporated to improve the validity of the instrument. Also, Cronbach Alpha reliability method was used to determine the internal consistency of the instrument. The reliability coefficient index of the instrument was 0.94 , which was considered adequate.

The 625 copies of questionnaire were administered to the respondents by the researcher with the aid of six research assistants who were briefed by the researcher on what to do. The researcher and the research assistants handed over copies of the instrument to all the respondents and allow two weeks for the completion and retrieval. At the end of the two weeks, 568 copies of the questionnaire were collected and used for the analysis. The others could not be retrieved as some of the respondents were not available at the period of retrieval and some could not find their questionnaires.

The data gathered from the questionnaire were analyzed using descriptive statistics of mean in order to answer the research questions. Inferential statistics of one way analysis of variance (ANOVA) was used to analyze hypothesis 1 while z-test was used to test hypothesis 2 at 0.05 level of significance. ANOVA was used to analyse hypothesis 2 because the variables tested were more than two while z-test 
is used to test two variables with large subjects.

In order to determine the extent of possession of the skills in relation to the research questions, a decision rule based on real limit of numbers was used to interpret the mean of each item response. The real limit of means is stated below;

Response Rating X Real Limits

- Very High Extent 5. 5-5.00

- High Extent 4. 3.5-4.49

- Moderate Extent 3. 5-2.49

- Low Extent 2. 1.5-2.49

- No Extent 1.00-1.49

For null hypothesis 1, where the calculated F-value is less than the F-critical value, the null hypothesis is accepted and if the calculated F-value is greater than the F-critical value, the hypothesis is rejected. Regarding null hypothesis 2, where the calculated $z$-value is less than the $z$-critical value, hypothesis is acceptable. However, where the calculated tvalue is equal to or greater than the t-critical value, the hypothesis is rejected [10].

\section{Results and Discussion}

This section presents the analysis of the data collected in respect of the study. The analysis is in two phases. Phase A Answering of Research Questions and Phase B - Hypotheses Testing.

\subsection{Research Question One}

Analysis of Extent Small Business Operators in Delta State Exhibit Time Management Skills

Table 1. Mean Scores of Small Scale Business Operators in Delta State on the Extent they exhibit Time Management Skills.

\begin{tabular}{|c|c|c|c|}
\hline $\mathbf{S} / \mathbf{N}$ & Time Management Skills & Mean & Decision \\
\hline 1. & Ability to prioritize your activities & 4.22 & High Extent \\
\hline 2. & Ability to plan your daily task & 4.36 & High Extent \\
\hline 3. & Ability to track you due dates & 4.08 & High Extent \\
\hline 4. & Ability to determine ways of keeping track of follow up & 4.13 & High Extent \\
\hline 5. & Ability to focus on task to be accomplished & 4.24 & High Extent \\
\hline 6. & Ability to complete task within stipulated time & 4.26 & High Extent \\
\hline 7. & Ability to evaluate time spent on task & 4.23 & High Extent \\
\hline 8. & Ability to carry out multi task & 4.15 & High Extent \\
\hline 9. & Ability to create personal road map not to clash with business time & 3.99 & High Extent \\
\hline 10. & Ability to find out where you are wasting time & 3.93 & High Extent \\
\hline 11. & Ability to eliminate your personal time waster & 4.10 & High Extent \\
\hline \multirow[t]{2}{*}{12} & Ability to increase your productive time & 4.20 & High Extent \\
\hline & Grand Mean & 4.16 & High extent \\
\hline
\end{tabular}

The data presented in Table 1 revealed that the mean scores of the respondents ranged from 3.93 to 4.36 with a grand mean of 4.16. All the items in $1-12$ with mean scores that ranged from 3.93 to 4.36 were assessed by respondents as of High Extent. With the grand mean of 4.16 which falls within 3.5-4.49, it indicated that Delta State small scale business operators' possession of time management skills were generally of High Extent.

\subsection{Research Question Two}

Analysis of Extent Small Business Operators in Delta State Exhibit Self Motivation Skills

Table 2. Mean Scores of Small Scale Business Operators in Delta State on the Extent they Possess Self Motivation Skills.

\begin{tabular}{|c|c|c|c|}
\hline $\mathbf{S} / \mathbf{N}$ & Self motivation skills & Mean & Decision \\
\hline 1. & Ability to believe in yourself & 4.05 & High Extent \\
\hline 2. & Ability to think positively & 4.09 & High Extent \\
\hline 3. & Ability to set your goals & 4.13 & High Extent \\
\hline 4. & Ability to realize your unwanted resolution & 3.84 & High Extent \\
\hline 5. & Ability to commit yourself to your goals & 3.74 & High Extent \\
\hline 7. & Ability not to fall prey to your mood & 4.11 & High Extent \\
\hline 8. & Ability to appreciate your present self & 4.00 & High Extent \\
\hline 9. & Ability to challenge your belief & 3.99 & High Extent \\
\hline 10. & Ability to produce circumstance necessary to arrive at desire outcome & 3.81 & High Extent \\
\hline 11. & Ability to withstand pressure & 4.19 & High Extent \\
\hline 12. & Ability to keep record of your progress & 3.91 & High Extent \\
\hline \multirow[t]{2}{*}{14} & Ability to look back & 4.10 & High Extent \\
\hline & Grand Mean & 3.99 & High Extent \\
\hline
\end{tabular}


Data presented in Table 2 showed that the mean scores of the respondents ranged from 3.74 to 4.19 with grand mean of 3.99. Small scale business operators responded to item 1, to 14 with mean scores ranging from the least of 3.81 to the highest of 4.19 and all were assessed as "High Extent". Since the grand mean is 3.99 , it falls between 3.5 and 4.49 which implies that Delta State small scale business operators' possession of self motivation skills are generally of "High Extent".

\subsection{Testing of Hypotheses}

Two hypotheses were formulated and tested at 0.05 level of significance to provide useful information for the study.

\subsubsection{Null Hypothesis One}

To test hypothesis 1 , the mean values of the three groups were compared using the Analysis of Variance (ANOVA) and the data is presented in Table 3.

Table 3. Summary Table of Analysis of Variance (ANOVA) for Hypothesis 1.

\begin{tabular}{|c|c|c|c|c|c|c|c|}
\hline \multicolumn{8}{|c|}{ ANOVA: Single Factor } \\
\hline \multicolumn{2}{|c|}{ Respondent Groups } & Count & \multicolumn{2}{|c|}{ Sum } & \multicolumn{2}{|c|}{ Average } & Variance \\
\hline \multicolumn{2}{|l|}{ Below $1^{\text {st }}$ degree } & 12 & \multicolumn{2}{|c|}{48.57063712} & \multicolumn{2}{|c|}{4.047553093} & 0.024615908 \\
\hline \multicolumn{2}{|l|}{ B.Sc/HND } & 12 & \multicolumn{2}{|c|}{51.63636364} & \multicolumn{2}{|c|}{4.303030303} & 0.028403873 \\
\hline \multicolumn{2}{|c|}{ Above $1^{\text {st }}$ Degree/HND } & 12 & \multicolumn{2}{|c|}{53.16} & \multicolumn{2}{|c|}{4.43} & 0.005692929 \\
\hline Source of variation & S.S & Df & Ms & $\mathrm{F}$ & P-Value & z-crit & Decision \\
\hline Between groups & 0.910622 & 2 & 0.45531109 & 3.26469452 & 4.9730107 & 3.284918 & Accepted \\
\hline Within groups & 0.64584 & 33 & 0.019570903 & & & & \\
\hline Total & 1.556462 & 35 & & & & & \\
\hline
\end{tabular}

$\mathrm{P}<0.05$

From the analysis of variance in Table 3 , the calculated Fvalue is 3.264 and F-crit is 3.284 . Since the F-value (3.264) is less than F-crit of (3.284), the null hypothesis is accepted. On the basis of this analysis, it can be concluded that there is no significant difference in the mean ratings of small scale business operations in Delta State on their possession of time management skills as a result of their academic qualifications.

\subsubsection{Research Hypothesis Two}

To test hypothesis 2 , the mean values of the two groups were compared, using the z-test statistic and the data is presented in Table 4.

Table 4. Summary Table of z-test Analysis of Hypothesis 2.

\begin{tabular}{|c|c|c|c|c|c|c|c|}
\hline Respondents & $\mathbf{N}$ & $\mathbf{X}$ & SD & Df & z-cal & z-critical & Decision \\
\hline Urban & & 3513.95 & 1.01 & 566 & 1.289 & +1.961 & Accepted \\
\hline Female & & 2174.06 & 0.95 & & & & \\
\hline
\end{tabular}

From the analysis in Table 4, it can be observed that the tcal (1.289) is less than the $\mathrm{z}$-crit $( \pm 1.961)$, therefore the null hypothesis that there is no significant difference in the mean ratings of urban and rural small scale business operators in Delta State on their possession of self motivation skills is upheld.

\section{Discussion}

The analysis of research question one, shown in Table 1 indicates that small scale business operators' exhibition of time management skills is generally of high extent. The finding is in agreement with [2] which stated that the ability to plan one's day is particularly important for a small business set up. Adidu and Olanny [6] also agreed that a successful entrepreneur has a good sense of timing. They believe that "time is money" and not easy to recover if wasted and the entrepreneur is over conscious about timely arrangement with all stakeholders.

The result of the analysis of research question two as shown in Table 2 reveals that small scale business operators' exhibition of self motivation skills is of high extent. This is in agreement with [2] that to succeed in business you must be a self starter with a clear desired goal in mind. You therefore must have extra drive and commitment to make sure that you are taking the necessary steps to make your dream of a successful business a reality. Culming [11] is also in agreement with the findings when he opined that people have varying reason why they go into business and said that man's prime motive is economic; to be able to meet his physiological needs and support a family ideally in ever increasing comfort, ambition therefore plays a vital role in the sense of the desire to succeed in managing his business.

The results of the two null hypotheses revealed that urban and rural small scale business operators in Delta State did not differ significantly on their mean rating of the extent they exhibit self motivation skills and time management skills as a result of the academic qualifications. This means that location and academic qualifications have no influence over time management skills and self-motivation skills of small scale business operators in Delta State of Nigeria.

\section{Conclusion}

In the light of the findings of this study, the following conclusions are made: 
- That time management skills are paramount skills and to a high extent needed by small scale business operators for the successful management of their businesses.

- That self motivation skills are salient in nature but at the same time very important for the management and success of small scale businesses.

- That small scale business operators did not differ significantly as a result of their location and their academic qualifications on their mean ratings of the extent they possess time management skills and self motivation skills.

\section{Recommendations}

Based on the findings and conclusions from the study, the following recommendations were made:

i Curriculum planners should incorporate time management and self motivation skills into the curriculum of entrepreneurship programme both at the secondary school and tertiary levels in Business Education so that prospective entrepreneurs can effectively manage their enterprises.

ii Workshops and seminars should be organized for operators of small scale business owners by the agencies responsible for the development of small businesses at all levels of government to create in-depth knowledge and technical know-how on time management and self motivation skills.

iii Professional bodies such as Association of Small and Medium Entrepreneurs (NASME) should organize their members coherently with the view to guiding them through dissemination of relevant and up-to date information on time management and self motivation skills possessed for successful management of businesses.

\section{References}

[1] G. O. Onajite, Assessment of critical entrepreneurial skills possessed by small scale business operators in delta state of Nigeria. International Journal of Management Sciences, Vol.5, No.12, 2015, pp. 795-804.

[2] B. A, Agbonifoh, The business enterprise in Nigeria. Lagos: Longman, 2009.

[3] O. Ademola, Enhancing entrepreneurship skills through business education programme in information technical era. Business Education Book of Reading. Vol.1, No.5, 2005, pp. 56-70.

[4] K. Tijani-Alaiwe, Entrepreneurship small and medium enterprises. Ikeja Lagos: Sentina press Ltd, 2004.

[5] G. O. Uloko, Time management: A skill. Journal of Nigeria Institute of Management (NIM), Vol.12, No.6, 2009, pp. 1014.

[6] F. A. Adidu, and P. A. Olanye, Basic small business entrepreneurship. Agbor: Royal Palace Publications, 2006.

[7] C. I. Onwuchekwa, Organizational behaviour. Enugu: ZikChuks Nig, 2000.

[8] L. E. Ekpenyong, The impact of personality variance on work place motivational strategies need for school base intervention. University of Benin Education Journal, Vol. 5, No.2, 2004, pp. 1-18.

[9] E. C. Osula, Principles and Practice of small business management: A didactic approach. Nsukka: Fillach Publishing Company, 2001.

[10] I. Owie, Fundamental of statistics in education and the social science. Benin City: Mindix Publishers, 2001.

[11] M. W. Culming, The theory and practice of personnel management. London: William Heinemann Ltd, 2006. 